\title{
Effects of Nurse-Police Facilitated Rape Education on Rape Myths Acceptance, Rape Victim Empathy and Rape Risk Behaviors of Adolescents
} Adesola A. Ogunfowokan, FWACN, RN, $\mathrm{PhD}^{1 *}$, Mary O. Obiyan, MSc, $\mathrm{PhD}^{2}$, Omowumi R. Salau, RN, MScN ${ }^{3}$

\author{
${ }^{1}$ Department of Nursing Science, College of Health Sciences, Obafemi Awolowo University, Ile-Ife, Nigeria \\ ${ }^{2}$ Department of Demography and Social Statistics Faculty of Social Sciences Obafemi Awolowo University, Ile-Ife, Nigeria \\ ${ }^{3}$ Department of Nursing Science, College of Health Sciences Obafemi Awolowo University, Ile-Ife, Nigeria
}

DOI: $10.36348 /$ sjnhc.2021.v04i01.002

| Received: 06.01.2021 | Accepted: 18.01.2021 | Published: 19.01.2021

*Corresponding author: Adesola A. Ogunfowokan, FWACN, RN, PhD

\section{Abstract}

The study aimed at determining the effectiveness of rape prevention education facilitated by a police officer and/or a school nurse at reducing rape myths acceptance, improving rape victim empathy, and reducing rape risk behaviors among school adolescents. Quasi-experimental design with repeated measures was used and it was conducted among 228 adolescents in three public high schools in Ile-Ife, Nigeria. The adolescents were grouped into: Control Group; Nurse Facilitated Group; and Nurse-Police Facilitated Group. Rape Discourse Education (RaDE) was conducted for the Nurse Facilitated Group and the Nurse-Police Facilitated Group and data collection was in four waves. Findings showed significant effect on rape myths acceptance $(\eta p 2=0.12)$ more than on other outcome variables and the effect was observed up to a six-month follow-up. Implication for rape prevention education in the school setting is documented.

Key words: Adolescents, Police Officer, Rape Discourse Package, Rape Education, Rape Myths Acceptance, Rape Risk Behaviors, Rape Victim Empathy, School Nurse.

Copyright (C) 2021 The Author(s): This is an open-access article distributed under the terms of the Creative Commons Attribution 4.0 International License (CC BY-NC 4.0) which permits unrestricted use, distribution, and reproduction in any medium for non-commercial use provided the original author and source are credited.

\section{INTRODUCTION}

Rape is a public health problem that has been reported in many parts of the world [1] and has been considered a rising public menace among high school students in Nigeria [2]. The 2018 National Health and Demographic Survey results indicated $9 \%$ prevalence among women aged, 15 - 49 years [3] but this does not cover other age groups in Nigeria. Empirical studies have also reported prevalence of rape of adolescent girls in different Nigerian settings to be between $10.6 \%$ and $21 \%$ [4-5]. Adolescent boys have been identified as perpetrators [6], and adult rapists have been reported to commence the act of rape at adolescent ages [7]. In a study conducted among high school adolescent boys in Nigeria, findings revealed that some of the boys raped their female intimate partners and also invite their friends to participate in the act of rape [8].

In Nigeria, rape has been attributed to the societal beliefs and norms of male dominance, acceptance of rape myths, and the patriarchal nature of the society [9]. Rape myths, such as 'a girl who dresses half-nakedly is asking to be raped' and 'rape happens when a boy's sex drive goes out of control', are used to shift blame of rape from perpetrators to victims thereby contributing to the pervasiveness of the act in the society [10]. Acceptance of rape myths has been widely reported to correlate to poor rape victim empathy, blaming the victim, and exonerating the perpetrator [11]. Rape risk behaviors which may be either perpetration risk behavior or victimization risk behavior have been documented to be linked with rape myths acceptance and rape victim empathy. The study of Mouilso and Calhoun [12] has shown that perpetrators of sexual aggression consistently report higher scores on measures of psychopathy and acceptance of rape myths relative to non-perpetrators. Dispelling rape myths and improving victim empathy, most especially among young generations, are essential to avoiding behavior that is prone to victimization or perpetration, which can be achieved through rape prevention education.

As far back as 2003, there has been an increased emphasis on schools to implement evidencebased programs [13]. MEDLINE search of Gavine, Donnelly, \& Williams [14] identified almost as four times as many records of school-based violence prevention programs published from 2002 onward compared to studies published prior to 2002. The 
review of 21 studies conducted in the United States found limited evidence of the effectiveness of universal school-based programs in the primary prevention of violence in 11- to 18-year-olds; but those that combined social development and social norms approaches appeared to be the most effective [14].

Internationally, the results of a systematic review of 140 outcome evaluations on prevention strategies for sexual violence perpetration showed that three programs (Safe Dates; Shifting Boundaries; and funding associated with the 1994 U.S. Violence Against Women Act) demonstrated significant effects on sexually violent behavior [15]. The Safe Dates study was a randomized controlled trial that used 10-session curriculum focusing on prevention of dating violence and was conducted among 8th and 9th graders with follow-up data collected over 4 years [16 -18]. The Safe Dates study showed reductions in sexual dating violence perpetration and victimization among the adolescents four years later [18]. The Shifting Boundaries, building level intervention study was a randomized controlled trial classrooms-based dating violence prevention programme conducted among 6th and 7 th graders with follow-up data collected over a period of 6 months [19 - 20]. The results of the Shifting Boundary Study showed a reduction in perpetration and victimization of sexual harassment and peer sexual violence as well as reduction in dating sexual violence victimization [20]. The 1994 Violence Against Women Act funding was a grant distributed by the US Department of Justice for the purpose of improving criminal enforcement, victim advocacy, and state and local capacity [21]. The 1994 grant study was conducted between 1997 and 2002 with data collected from reports from police jurisdictions and findings showed reduction in annual rape rates.

In Nigeria, educational programs that effectively improve empathy toward rape victims or reduce rape myths acceptance and rape risk behaviors among adolescents are scarce. There are documented school-based sensitization and awareness programs for high school students by non-governmental organizations such as the Media Concern Initiative [22], the STER [23] and the Mirabel Centre [24-25]. The sensitization programs were usually conducted for students' representatives from various schools. Also, these organizations made use of peer educators and other trained sexual assault prevention experts to deliver the education. These sensitization programs were never followed up to determine the outcome of the programs. Anecdotal evidence has shown that there is no school-based curriculum for rape education in Nigeria, neither are we aware of any sensitization program that made use of the school nurse and the police as facilitators.

There is documented evidence on the positive effect of school nurses in improving health of learners through health education and support services. The study of Al-Yateem, Attia, AL-Yafei, Mohammed, \& Mahmood [26] found improved knowledge of healthy eating and adoption of more healthy eating behaviors post school nurse education. Also, the 6-session school nurse-delivered counseling intervention conducted among high school students by Pbert, Druker, Gapinski, et al., [27] shows an improved obesogenic behavior among the students [28]. Furthermore, the study of Raible and others [28] showed an increase in the school nurse-student's discussion around prevention of relationship abuse and such discussion was accepted by both the nurses and the students. Aside from this, the Nigeria Police Act [29] has highlighted the preventive roles of the police in the community with some senior police officers giving sensitization talks via mass media to the public on prevention of some criminal activities, including rape. In North America, the police were recognized as effective resource person in schools for classroom presentations and for reduction of crime, with the resultant benefits of increased safety in and around the schools [30]. However, recent findings have shown that the presence of school-based law enforcement officers who are also called school resource officers have led to lower morale and interference with students' ability to learn [31]. Similarly, the School-to-Prison Pipeline has been documented to represent a threat to students' physical, cognitive and emotional health and safety most especially among black students [32]. In Nigeria, there are ongoing discussions on the adoption of community/school policing most especially in troubled areas, in order to protect citizens and school children from bandits [33-35].

Judging by the unique characteristics of the Nigerian tradition and by assessing the need for effective reduction of rape in the country, we are of the opinion that rape education delivered by the school nurse and a police officer will be a result-oriented program. Police officers are knowledgeable about laws regarding rape, and its prosecution process. They are also competent to share their experiences of rape cases whose perpetrators have been prosecuted. Rape education by police officers in the school will also bring the reality of rape and its consequences to school adolescents and lay the foundation for evidence-based interventions to changing societal norms that encourage rape. Also, the school nurse has medical knowledge of the health consequences of rape; such knowledge can be complemented with the legal knowledge of the police in delivering effective rape prevention education. Therefore, we are of the opinion that a rape prevention education that addresses the nature of rape as well as its medical and legal consequences, through collaborative efforts of the police and the school nurse, will be a comprehensive, result-oriented rape prevention program.

We therefore designed a Rape Discourse 
Package (RADiP) that consisted of statements on rape myths acceptance, rape victim empathy, rape risk behavior, laws addressing rape in the country, and other rape information. The essence of the package was such that it can be delivered to school adolescents in form of a discussion within four days and at one hour per day as against some interventions with longer implementation duration (e.g. Moor study - 6 hours [36]; Taylor et al. study - 6 to10 weeks [19]; Foshee, et al., study - 10 sessions of 45 minutes each [37]. The entire design of the study was with a view to deliver rape education to school adolescents within the shortest time possible using the school nurse and police officer as facilitators for reduction of rape myths acceptance, rape victim empathy and rape risk behavior among the students.

\section{STUDY PURPOSE}

The purpose of this study was to compare the effectiveness of a school-nurse facilitated rape prevention education with a school nurse-police facilitated education, as well as no education group in reducing rape myths acceptance, increasing rape victim empathy, and reducing rape risk behaviors among adolescents. We therefore hypothesized that:

H1: The baseline mean scores for rape myths acceptance, rape victim empathy and rape risk behaviors of adolescents in the school nurse-police facilitated education will increase more than the scores for the adolescents in the school nurse facilitated education group at immediate post-intervention (Follow-up 1).

H2: The immediate post-intervention mean scores of the adolescents in the intervention groups (school nurse facilitated group and school nurse-police facilitated group) will be sustained at 3 month (Followup 2) and 6 month (Follow-up 3) post-interventions in the outcome variables of rape myths acceptance, rape victim empathy and rape risk behaviors.

H3: There is a significant difference between the two intervention and control groups in the outcome measures of rape myths acceptance, rape victim empathy and rape risk behaviors.

\section{METHODS}

Ethical approval for this study was obtained from the Institute of Public Health, Health and Research Ethics Committee, Obafemi Awolowo University, Nigeria. Written consent was obtained from the adolescents that were more than 18 years old and parents/guardians whose adolescents were less than 18 years. Assent of adolescents less than 18 years were also obtained. Permission to conduct the study was received from the authority of the study schools. During the course of the study, there was no observed case of psychological disturbance in any of the adolescents who might have recalled past experiences of rape; hence, no referral was made and no psychological support was given to any of the adolescents.

The study was a pilot one which employed quasi-experimental design with repeated measures. It was conducted among adolescent boys and girls aged 13-19 years in three public high schools in Ile-Ife, Osun State, Nigeria. These high schools are government owned and students are usually those from average or low socio-economic status families. The schools are also coeducational.

The necessary study sample size was calculated using $\mathrm{G}^{*}$ power software 3.1.9.7 [38] by setting the power at 0.85 with medium effect size of 0.5 and an alpha of 0.05 [39]. A sample size of 177 determined based on power analysis, and taking into account $30 \%$ attrition rate [40] was obtained. Therefore, a total of 228 adolescents were recruited for the study Recruitment was carried out by asking the adolescents to indicate if their age range was between 13 and 19 years and if they were willing to participate in the study. Random selection of those in the age range and those willing to participate in the study was carried out in each of the schools based on their population size and gender. A total of 76 adolescents ( 38 males, 38 females) were selected from Grades 10 and 11 from each of the three high schools. Those in grade 12 were excluded from the study because they would have completed high school at the time of completing data collection.

Adolescents in one of the schools were assigned the control group while those in the other two schools were assigned the intervention groups (school facilitated group and school nurse-police facilitated group). In addition, a government registered male school nurse and a female police officer were enrolled into the study as facilitators. The nurse and the police were recruited base on the recommendations of their immediate superiors bearing in mind their previous involvement in sexual violence prevention and management.

Data for this study were collected through adapted Rape Questionnaire (RaQ). The RaQ was adapted from the Updated Illinois Rape Myths Acceptance Scale (IRMA) [41] and Rape Victim Empathy Scale [42]. The rape myths acceptance scale reliability coefficient for the subscales in previous study ranged from 0.64 to 0.80 , while the overall Cronbach's alpha for the measure was $0.87[41]$. The rape victim empathy scale reliability coefficient in previous studies was found to be $0.84-0.89$ [42] and 0.80-0.89 [43]. The Rape Myths Acceptance Scale was adapted by replacing 'woman' and 'man' in the scales with 'boy' and 'girl' since it is to be used among adolescents. The questionnaire had 4 sections. The first section had 19 questions which explored the demographic characteristics of the adolescents. The second section contained 22, 5-point Likert scale (Strongly Agree -1 to Strongly Disagree -5) questions that explored rape 
myths acceptance. The third section contained 11 rape victim empathy scale questions on a Likert scale of 1 (Agree Very Strongly) to 6 (Disagree Very Strongly).

The last section which was developed from review of literature had 21 questions and explored rape risk behavior. The rape risk behavior was divided into two. Firstly, the 15 rape victimization risk reduction behavior questions to be answered by girls and were framed thus: "Please indicate what you did in the past 3 months to prevent being at risk of falling victim of rape" Examples of such risk reduction behaviors are: "I avoided late night outings"; I avoided being alone with a man that I do not trust". Secondly, the 7 rape perpetration risk reduction behavior questions to be answered by boys were framed thus: "Please indicate what you did in the past 3 months to prevent being at risk of perpetrating rape". Examples of such risk reduction behaviors are: "I always respected the view of my girl lover whenever she was not interested in sex"; I avoided staying alone with a girl whenever I had sexual urge and my instincts tells me that my act might be tantamount to rape" The rape risk behaviors were assessed on a 4-point Likert Scale of Never (1), Sometimes (2), Often (3) and Always (4).

\section{Study Process}

The study data collection and education came up between May, 2017 and January, 2018. Attrition rates of the adolescents at 3 and 6 months were $16 \%$ and $27 \%$ respectively.

\section{Rape Education \\ Training of Facilitators and Research Assistants}

Prior to the education, the facilitators (school nurse and police officer) were trained by the investigators at a specified venue at the workplace of the principal investigator. They were trained on how to use the curriculum (Rape Discourse Package - RaDiP) for educating the adolescents. PowerPoint projection as would be used for educating the adolescents was used for the training. Issues around the training contents were clarified and hardcopy of the curriculum was shared with the facilitators as well as the PowerPoint slides. Topics for presentation by each of the facilitators in the paired facilitation were assigned to them. The training was for a period of 8 hours.

The education was carried out among the adolescents in the intervention groups. The nurse facilitated the first intervention group and later paired up with the police to facilitate the second intervention group. For the paired facilitation, the topics were distributed as shown in Table 1 while, for the lone facilitation, the school nurse delivered the entire topics.

Table-1: Topics Facilitated by the Nurse and the Police during Rape Education

\begin{tabular}{|l|l|}
\hline School Nurse & Police Officer \\
\hline Definition of rape & Forms of rape \\
\hline Potential victims and perpetrators of rape & Settings for rape \\
\hline Consequences of rape & $\begin{array}{l}\text { Reported and prosecuted cases of rape among } \\
\text { adolescent girls }\end{array}$ \\
\hline Examination of rape myths statements & Examination of extract from Nigerian rape laws \\
\hline Examination of rape victim empathy statements & Rape perpetration risk behavior \\
\hline Final resolution & Rape victimization risk behavior \\
\hline
\end{tabular}

The education was carried out in a single day for a period of 3 hours in each of the school halls. The plan for the education was for a period of 4 days at one hour per day but, the Head of the study schools insisted the education should be compressed to few hours in a day. Public address system was used to increase the audibility of the facilitators. The education was facilitated using PowerPoint projection while, handouts (abbreviated version of the $\mathrm{RaDiP}$ and PowerPoint slides) were distributed to the adolescents. Facilitation of the sessions was by projecting information under each topic and guiding the adolescents in discussing the information. The discussion allowed for correction of erroneous views and myths about rape. In each of the intervention schools, both male and female adolescents were educated in the same group as it is the practice in the school learning environment. Bringing both sexes together in the same group allowed for extensive gender-based discussion.

The RaQ was used to collect data at baseline, immediately post curriculum delivery, then at 3- and 6- month post-interventions. At each data collection stage, the participating adolescents were gathered in the school hall and questionnaires administered to them under examination conditions.

\section{DATA ANALYSIS}

Data entry was done using Epi Data Software Version 3.1 9, while Statistical Package for Social Sciences (SPSS) version 23 [44] was used for data analysis. There were very few missing values which were treated using mean substitution [45]. The normality of the test was tested for using Kolmogorov smirnov and Shapiro-wilk test which gave values of 0.20 and 0.63 respectively. Descriptive statistics were used to determine the mean scores for rape myths acceptance, rape victim empathy, rape victimization risk behavior and rape perpetration risk behavior. Independent-samples t-test was carried out to determine the significant mean difference between the groups by their outcome variables. The overall effect of the education and comparison between the control and 
intervention groups was determined using one-way repeated measure MANOVA.

\section{RESULTS}

The questionnaire was pretested in the course of this study being an adapted tool and also for being used in a different setting. The internal consistencies using Cronbach's alpha were: 0.86 (rape myths acceptance), 0.76 (rape victim empathy), 0.9 (rape victimization risk behavior) and 0.9 (rape perpetration risk behavior). Overall Cronbach's alpha for the instrument was 0.71 .

The demographic characteristics showed that the adolescents in the three groups were not significantly different $\left(X^{2}=3.56 ; p=0.17\right)$. Majority of them were in the middle-age adolescent stage $(91.7 \%)$ with mean age of $16.1 \pm 1.2$ years. Ten $(4 \%)$ of the adolescents reported they had been raped while, 12 (5\%) reported they had raped someone else. The Likert Scale scores on rape myths acceptance ranged from 22 to 110 with higher scores indicating decrease rape myths acceptance. The rape empathy scores ranged from 11 to 66 with higher scores indicating strong empathy for rape victims. Also, responses to rape risk behaviors were scored from 1 to 64 for girls and 1 to 28 for boys. Higher scores indicated low risk for rape victimization for girls and low risk for rape perpetration for boys.

\section{Hypothesis 1}

At immediate post-intervention (Table 2), the adolescents in the school nurse-police facilitated group had reduced rape myths acceptance as their rape myths mean scores significantly increased from 43.3 at baseline to $65.7(\mathrm{t}=9.4, \mathrm{p}=0.001)$. Similar increase was also observed for adolescents in nurse-facilitated group (Mean increase from 42.3 to $72.2, \mathrm{t}=13.5$, $=$ $0.001)$. However, the increase in the mean scores of adolescents in the nurse-facilitated group is higher than those in the school-nurse-police facilitated group. For other outcome measures, no significant changes at immediate post-intervention were observed for them ( $p$ $>0.05)$.

Table-2: Mean Scores of Outcome Variables at Immediate Post-Intervention for the Two Intervention Groups

\begin{tabular}{|c|c|c|c|c|c|c|}
\hline & \multicolumn{2}{|l|}{ N-PFG } & \multirow{3}{*}{$t / p$} & \multicolumn{2}{|l|}{ NFG } & \multirow[t]{3}{*}{$t / p$} \\
\hline & Baseline & Immediate Post & & Baseline & Immediate Post & \\
\hline & M/SD & M/SD & & M/SD & M/SD & \\
\hline RMA & $43.3 / 12.3$ & $65.7 / 16.8$ & $9.4 / 0.001$ & $42.3 / 10.6$ & $72.2 / 16.2$ & $13.5 / 0.001$ \\
\hline RVE & $48.9 / 10.7$ & $50.0 / 12.7$ & $0.56 / 0.57$ & $47.6 / 11.0$ & $45.3 / 14.0$ & $1.11 / 0.27$ \\
\hline RVRB & $45.5 / 9.9$ & $39.5 / 16.8$ & $1.86 / 0.07$ & $38.9 / 14.6$ & $36.8 / 16.4$ & $0.60 / 0.55$ \\
\hline RPRB & $20.2 / 6.6$ & $18.5 / 6.9$ & $1.05 / 0.30$ & $20.7 / 6.8$ & $22.5 / 6.4$ & $1.16 / 0.25$ \\
\hline
\end{tabular}

KEY: N-PFG = Nurse-Police Facilitated Group; NFG = Nurse Facilitated Group; RMA = Rape Myths Acceptance; RVE = Rape Victim Empathy; RVRB = Rape Victimization Risk Behavior; RPRB = Rape Perpetration Risk Behavior.

\section{Hypothesis 2}

At 3- and 6-month follow-ups, (Table 3) the immediate post-intervention rape myths acceptance means scores for the two intervention groups were not sustained as they dropped less than the scores in the immediate post-interventions. Although, these scores are more than the baseline scores, which means that the education in the two groups had significant effect on the rape myths acceptance of the adolescents up to 6-month post-intervention. Also, the rape victim empathy of the adolescents in the nurse-police facilitated group was not sustained at 3 and 6 months as a result of reduction in immediate post-intervention scores for the outcome variables. The rape victimization risk behavior and rape perpetration risk behavior were sustained at 3- and 6months post intervention; however, it should be noted that these mean scores are less than the mean scores at baseline. Therefore, the education had no significant effects on the adolescents' rape risk behaviors.

Table-3: Mean Difference between Immediate Post-Intervention Scores, and Three- and Six-month Post-Intervention Scores for the Two Intervention Groups

\begin{tabular}{|l|l|l|l|l|l|l|}
\hline & N-PFG & \multicolumn{2}{l|}{ NFG } \\
\hline & Immediate Post & 3 Months & t/p & Immediate Post & 3 Months & t/p \\
\hline & M/SD & M/SD & & M SD & M/SD & \\
\hline RMA & $65.7 / 16.8$ & $59.5 / 14.4$ & $2.40 / 0.02^{*}$ & $72.2 / 16.2$ & $62.1 / 15.2$ & $3.76 / 0.001^{*}$ \\
\hline RVE & $50.0 / 12.7$ & $36.7 / 13.5$ & $6.24 / 0.001^{*}$ & $45.3 / 14.0$ & $47.3 / 12.5$ & $0.9 / 0.40$ \\
\hline RVRB & $39.5 / 16.8$ & $40 . / 3 / 14.9$ & $1.20 / 0.91$ & $36.8 / 16.4$ & $38.2 / 15.3$ & $0.4 / 0.73$ \\
\hline RPRB & $18.6 / 6.9$ & $17.3 / 7.3$ & $1.58 / 0.12$ & $22.5 / 6.4$ & $19.9 / 6.7$ & $1.7 / 0 / 10$ \\
\hline & Immediate Post & $\mathbf{6}$ Months & $\mathbf{t} / \mathbf{p}$ & Immediate Post & $\mathbf{6}$ Months & t/p \\
\hline RMA & $65.7 / 16.8$ & $59.9 / 15.5$ & $2.02 / 0.05^{*}$ & $72.2 / 16.2$ & $64.1 / 16.2$ & $2.86 / 0.005^{*}$ \\
\hline RVE & $50.0 / 12.7$ & $39.4 / 11.7$ & $4.9 / 0.001^{*}$ & $45.3 / 14.0$ & $44.2 / 12.5$ & $0.48 / 0.64$ \\
\hline RVRB & $39.5 / 16.8$ & $41.2 / 12.4$ & $0.4 / 0.7$ & $36.8 / 16.4$ & $41.6 / 16.2$ & $-1.15 / 0.26$ \\
\hline RPRB & $18.5 / 6.9$ & $18.6 / 6.6$ & $0.7 / 1.0$ & $22.5 / 6.4$ & $21.3 / 5.6$ & $0.87 / 0.39$ \\
\hline
\end{tabular}

*Significance is not due to improved outcome variables but due to reduction in mean scores 
KEY: N-PFG = Nurse-Police Facilitated Group; NFG = Nurse Facilitated Group; RMA = Rape Myths Acceptance; RVE = Rape Victim Empathy; RVRB = Rape Victimization Risk Behavior; RPRB = Rape Perpetration Risk Behavior.

\section{Hypothesis 3}

The general overview of the results shows that the education in both the nurse facilitated group and nurse-police facilitated group had significant effect on the rape myths acceptance of the adolescents as shown in Fig 1. No significant changes were observed for other outcome variables including that of the control group.

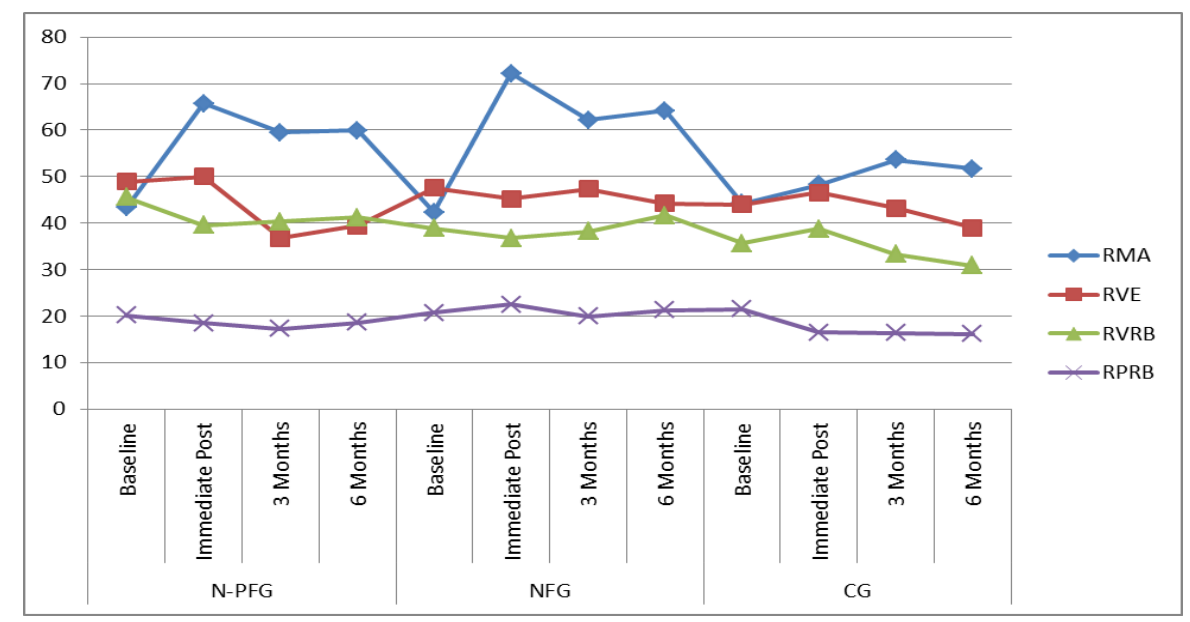

Fig-1: Combined Outcomes for both Intervention and Control Groups by their Mean Scores

KEY: N-PFG = Nurse-Police Facilitated Group; NFG = Nurse Facilitated Group; RMA = Rape Myths Acceptance; RVE = Rape Victim Empathy; RVRB = Rape Victimization Risk Behavior; RPRB = Rape Perpetration Risk Behavior.

Using, repeated measure MANOVA, overall impact of the education on rape myths acceptance showed a significant difference between the three groups $\left(\mathrm{F}(2,225)=15.21, \mathrm{p}=0.0001, \eta \mathrm{p}^{2}=0.12\right.$, Wilks' Lambda $=0.71)$. Multiple comparisons of schools for rape myths acceptance showed no significant difference between nurse-police facilitated group and nurse-facilitated group $(\mathrm{p}=0.90)$. For rape victim empathy, there was no significant difference between the three groups $(\mathrm{F}(2,225)=2.45, \mathrm{p}=0.08$, $\eta \mathrm{p}^{2}=0.02$, Wilks' Lambda $=0.97$. Also, no significant difference was found in the three groups for rape perpetration risk behavior $(\mathrm{F}(2,225)=2.45, \mathrm{p}=1.02$, $\eta p^{2}=0.01$, Wilks' Lambda $\left.=0.98\right)$ and rape victimization risk behavior, $(\mathrm{F}(2,225)=1.58, \mathrm{p}=0.21$, $\eta \mathrm{p}^{2}=0.01$, Wilks' Lambda $\left.=0.92\right)$. Tukey HSD comparison (Table 4) showed that the control group is different from the two intervention groups as they do not form the same sub-set. For other outcome variables, all the three groups form the same subsets and they are not significantly different from one another.

Table-4: Tukey HSD comparison of Study Groups

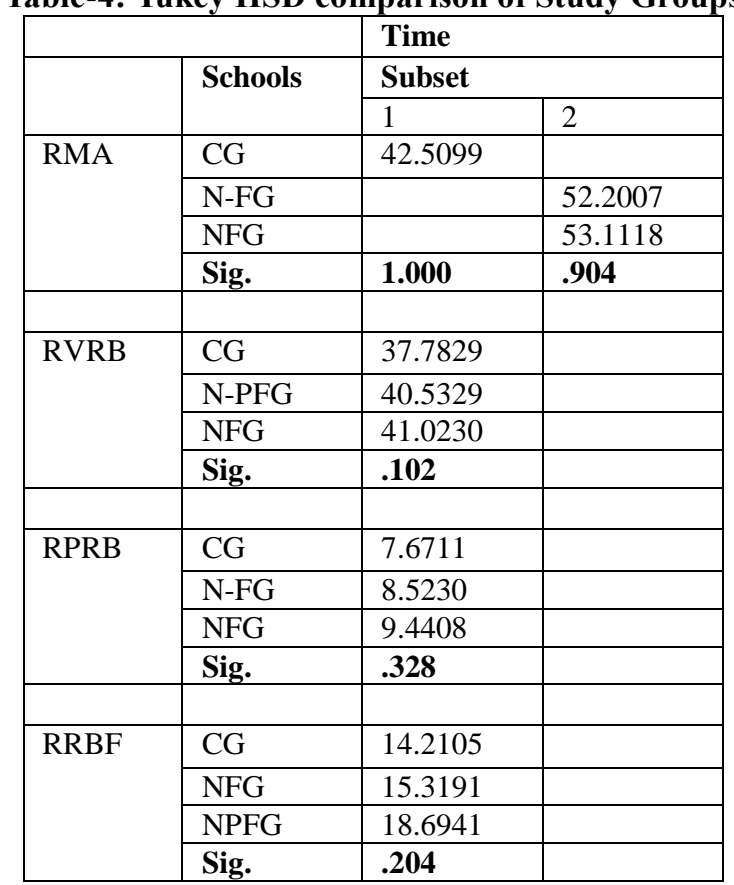


KEY: N-PFG = Nurse-Police Facilitated Group; NFG = Nurse Facilitated Group; RMA = Rape Myths Acceptance; RVE = Rape Victim Empathy; RVRB = Rape Victimization Risk Behavior; RPRB = Rape Perpetration Risk Behavior.

\section{DISCUSSION}

This pilot study was designed to determine the impact of rape prevention education facilitated by a nurse and a nurse-police pair respectively on rape myths acceptance, rape victim empathy and rape risk behavior of school adolescents. The results showed that there was a significant reduction in the rape myths acceptance of the adolescents in the intervention groups which was sustained till six months post-intervention. However, no significant changes in the rape victim empathy and rape risk behavior of the adolescents were observed.

Our study corroborated the results of previous studies $[46,47]$ which observed reduction in rape myths acceptance of college students post rape education. Judging by the short period of the education, it is pertinent to note that the reduction in the rape myths acceptance was observed up till six-month postintervention. Reducing rape myths acceptance is paramount among this age group because, they will grow into adults with proper understanding of rape, thereby supporting anti-rape campaign whenever they have the opportunity. The education delivered by the school nurse is as effective as the one delivered when the nurse was paired with the police. Therefore, the study is another indication that the school nurse can deliver rape education effectively to reduce rape myths acceptance among adolescents. The trend of bringing the police to schools for law enforcement, teaching, and counseling is gaining ground in some parts of the world most especially in North America [48-49]. However, there are some concerns in certain quarters on the negative effect that police presence in schools has on students' emotions and learning ability [31-32]. The concept of police presence in school is strange in many under-developed and developing nations like Nigeria. Currently, there are discussions in the political quarters on the adoption of community/school policing most especially in troubled areas to protect citizens and school children from bandits [33-35]. Although, we support the presence of police in schools in Nigeria most especially public schools, as there have been reports of increased violence in many public schools [50] but, certain crime prevention education such as rape prevention education can be handled by the school nurse.

The addition of a police presence in rape prevention education did not appear to have any significant effect beyond what the school nurse was providing. While we do not know of other studies that included police in such education, other studies have demonstrated positive impact of school nurses [28, 51]. Over the years, the school nurse, who is a health representative in school is noted for delivering health education and supporting learners and staff to adopt responsible health behavior. This study has shown that rape prevention education involving partnership between the school nurse and a police officer will improve RMA but not as much as if a school nurse delivers the education. We also observed that effective education by either the nurse or the police is a product of ability to effectively communicate and impart knowledge. Nursing education and practice is impregnated with many educational activities as nurses are involved in health education of their clients [52]. In Nigeria, police officers are involved in arrest and prosecution of offenders even though they are also supposed to get involved in prevention education as documented in the Police Act [29]. Interaction with some Nigerian police officers showed that educational technique is not part of the curriculum for Police training and this can explain why the impact of the education on the nurse-police facilitated group is lower than that of the nurse-facilitated group on rape myths acceptance outcome.

Insignificant impact of the education on rape victim empathy and rape risk behavior in both intervention groups was recorded in this study. Although positive outcome for rape victim empathy has been documented in some empathy-based prevention programs [46, 53] however, in the study of Moor [36], victim blaming was reported post rape education among high school students in Israel. Also, the systematic review study of DeGue, et al., [15, showed that majority of documented sexual violence prevention strategies which focused on increasing knowledge or changing attitudes had no evidence of effectiveness on sexually violent behavior even with rigorous evaluation design employed. Moor's study [36] also observed minimal self-reported behavioral changes post rape prevention education.

Rape is a multifaceted problem that requires multifaceted approach, more so in a patriarchal society as Nigeria. Improving rape victim empathy and reducing rape risk behavior among adolescents require continual education, mobilization and sensitization of the adolescents as well as the society at large. If the education delivered within a short period of time in the school as found in this study can improve rape myths acceptance up to six months post-intervention, then it is expected that rape prevention education that is embedded in the school curriculum can be a worthwhile effort. The education can be delivered as a yearly seminar by the school nurse either in the classroom setting or as extra-curricular activities.

This is the first time we are using the Rape Discourse Package (RADiP) and we are hopeful to conduct further testing to determine its effects among school adolescents in private schools using the school nurse as facilitator. Comparing this package with an already existing rape prevention education package to further verify its effectiveness using school nurses as 
facilitators is imperative. The RADiP can also be adapted in other settings and among other age groups, with focus on both genders as victims and perpetrators of rape.

\section{LIMITATIONS}

The study focused on adolescent girls as rape victims and adolescent boys as rape perpetrators. In Nigeria, reported cases of rape victimization of adolescent girls are more than those of boys, and the Nigerian penal and criminal code documents are silent on rape of men or boys but, it is explicit on rape of girls and women. Therefore, the contents of Rape Discourse Package and the questionnaire focused mainly on rape of adolescent girls. It is hopeful that in the future this Rape Discourse Package will be expanded to include information on rape of adolescent boys. Also, there was

\section{ACKNOWLEDGEMENT}

The authors acknowledge Sigma Theta Tau International for funding this project under Grant number: 12521.

\section{REFRENCES}

1. Folayan, M. O., Odetoyinbo, M., Brown, B., \& Harrison, A. (2014). Differences in sexual behaviour and sexual practices of adolescents in Nigeria based on sex and self-reported HIV status. Reproductive health, 11(1), 83.

2. Okagua, J., \& Alex-Hart, B. A. (2020). Sexual Abuse Amongst Secondary School Students in Port Harcourt, South-South Nigeria: A Rising Public Health Menace, Factors and Implications - Acta Scientific Paediatrics (ISSN: 2581-883X), 3(3). DOI: 10.31080/ASPE.2020.03.0224

3. National Population Commission (NPC) [Nigeria] and ICF. (2019). Nigeria Demographic and Health Survey 2018. Abuja, Nigeria, and Rockville, Maryland, USA: NPC and ICF.

4. Ogunfowokan, A. A., \& Fajemilehin, B. R. (2015). Experiences of sexual abuse by adolescent girls in Ife/Ijesa zone, Nigeria. Nigerian Journal of Health Sciences, 15(2), 89.

5. Alake, M. (October 4, 2018). 5 boys drugged and filmed 2 girls while raping them, but go scot free. Pulse, Retrieved from: https://www.pulse.ng/gist/metro/rape-injustice-5boys-drugged-and-filmed-2-girls-while-rapingthem-but-go-scot-free/xk61gp1

6. Ricks, J. M., \& DiClemente, R. J. (2015). Adolescent sex offenders. In Handbook of adolescent behavioral problems (pp. 577-593). Springer, Boston, MA. https://doi.org/10.1007/978-1-4899-7497-6_30

7. Young, A. M., Grey, M., \& Boyd, C. J. (2009). Adolescents' experiences of sexual assault by peers: Prevalence and nature of victimization occurring within and outside of school. Journal of Youth and Adolescence, 38(8), 1072-1083.

8. Ogunfowokan, A. A., Olagunju, O. E., Olajubu, A. O., Faremi, F. A., Oloyede, A. S., \& Sharps, P. W. a heavy reliance on self-reported data on rape risk behaviors rather than the actual behaviors, and this allowed for socially desirable responses. The education was also designed to be carried out in four days at one hour per day but it was compressed to a day for 3 hours.

\section{CONCLUSION}

Rape education delivered within a short period of time is effective in reducing rape myths acceptance among school adolescents up to 6 months postintervention while no significant effect was recorded for rape victim empathy and rape risk behaviors. The presence of the police in schools for rape education might not be necessary as the school nurse can effectively deliver the education.

(2016). Correlates of self-report of rape among male school adolescents in Ile-Ife, Nigeria. Journal of interpersonal violence, 31(4), 555-571.

9. Badejoko, O. O., Anyabolu, H. C., Badejoko, B. O., Ijarotimi, A. O., Kuti, O., \& Adejuyigbe, E. A. (2014). Sexual assault in Ile-Ife, Nigeria. Journal of the Nigeria Medical Association, 55(3), 254.

10. Tavrow, P., Withers, M., Obbuyi, A., Omollo, V., \& Wu, E. (2013). Rape myth attitudes in rural Kenya: toward the development of a culturally relevant attitude scale and "blame index". Journal of interpersonal violence, 28(10), 2156-2178.

11. Baldwin-White, A., Thompson, M. S., \& Gray, A. (2016). Pre-and postintervention factor analysis of the Illinois Rape Myth Acceptance Scale. Journal of Aggression, Maltreatment \& Trauma, 25(6), 636-651.

12. Mouilso, D. R., \& Calhoun, K. S. (2013). The Role of Rape Myth Acceptance and Psychopathy in Sexual Assault Perpetration Journal of Aggression, Maltreatment \& Trauma, 22(2) https://doi.org/10.1080/10926771.2013.743937

13. Wilson S. J., \& Lipsey, MW. (2007). School-based Interventions for Aggressive and Distruptive Behavior. Update of a Meta-Analysis. American Journal of Preventive Medicine, 33, S130-S143. https@//doi.org/10.1016/j.amepre.2007.04.011

14. Gavine, A. J., Donnelly, P. D., \& Williams, D. J. (2016). Effectiveness of universal school-based programs for prevention of violence in adolescents. Psychology of Violence, 6(3), 390.

15. DeGue, S., Valle, L. A., Holt, M. K., Massetti, G. M., Matjasko, J. L., \& Tharp, A. T. (2014). A systematic review of primary prevention strategies for sexual violence perpetration. Aggression and Violent Behavior, 19(4), 346-362.

16. Foshee, V., Bauman, K. E., Arriaga, X. B., Helms, R. W., Koch, G. G., \& Linder, G. F. (1998). An evaluation of safe dates, an adolescent dating violence prevention program. American Journal of Public Health, 88(1), 45-50.

17. Foshee, V. A., Bauman, K. E., Ennett, S. T., Linder, G. F., Benefield, T., \& Suchindran, C. 
(2004). Assessing the long-term effects of the safe dates program and a booster in preventing and reducing adolescent dating violence victimization and perpetration. American Journal of Public Health, 94(4), 619-624.

18. Foshee, V. A., Bauman, K. E., Ennett, S. T., Suchindran, C., Benefield, T., \& Linder, G. F. (2005). Assessing the effects of the dating violence prevention program "safe dates" using random coefficient regression modeling. Prevention Science, 6(3), 245-258.

19. Taylor, B., Woods, D., \& Mumford, E. (2011, October). Shifting boundaries: Final report on an experimental evaluation of a youth dating violence prevention program in New York City middle schools.Police Executive Research Forum. Retrieved from: https://www.ncjrs.gov/pdffiles1/nij/grants/236175. pdf

20. Taylor, B. G., Stein, N. D., Mumford, E. A., \&Woods, D. (2013). Shifting boundaries: an experimental evaluation of a dating violence prevention program in middle schools. Prevention Science, 14(1), 64-76.

21. Boba, R., \& Lilley, D. (2009). Violence against women act (VAWA) funding: a nationwide assessment of effects on rape and assault. Violence Against Women, 15(2), 168-185. http://dx.doi.org/10.1177/1077801208329146.

22. Media Concern Initiative. (2010). Rape Prevention for 1000 Children in Nigeria. Retrieved from: https://www.globalgiving.org/projects/rapeprevention-for-1000-children-in-nigeria/

23. Emeka, M. (2016, Sept., 5). \#Impact365: This group of young women are fighting to end rape. Retrieved from: https://ynaija.com/impact365group-young-women-fighting-end-rape/

24. Partnership for Justice. (2015a). Advocacy Visit to Schools in Lagos State to Create Awareness on Rape. Retrieved from: http://pjnigeria.org/mirabelcentre/advocacy-visit-to-schools-in-lagos-state-tocreate-awareness-on-rape.pjn/

25. Partnership for Justice. (2015b). Mirabel Centre takes war against sexual violence to Lagos schools. Retrieved from: https://pjnigeria.org/mirabelcentre/mirabel-centre-takes-war-against-sexualviolence-to-lagos-schools.pjn/

26. Al-Yateem, N., Attia, A. K. N., AL-Yafei, T., Mohammed, A. \& Mahmood, B. (2015). The impact of a school nurse intervention on adolescents' knowledge about healthy eating. British Journal of School Nursing 10 (6). https://doi.org/10.12968/bjsn.2015.10.6.280

27. Pbert, L., Druker, S., Gapinski, M. A., Gellar, L., Magner, R., Reed, G., Schneider, K., \& Osganian, S. (2013). A school nurse-delivered intervention for overweight and obese adolescents. The Journal of school health, 83(3), 182-193. https://doi.org/10.1111/josh.12014
28. Raible, C. A., Dick, R., Gilkerson, F., Mattern, C. S., James, L., \& Miller, E. (2017). School Nurse-

Delivered Adolescent Relationship Abuse Prevention. Journal of School Health, 87(7), 524530.

29. Law of Federation of Nigeria. The Police Act 1990. (2016, June). Retrieved from http://www.lawyard.ng/wpcontent/uploads/2015/11/CHAPTER-P19-

POLICE-ACT-and-subsidiary-Regulations-.pdf

30. Sampson, R. (2009). Bullying in schools. US Department of Justice. U.S. Department of Justice, Office of Community Oriented Policing. USA, San Diego. ISBN: 1-932582-11-8. Retrieved from: https://digitalcommons.unl.edu/cgi/viewcontent.cgi ?article $=1005 \&$ context $=$ usjusticematls

31. Advancement Project. (2013). Police in Schools are not the answer to the Newtown Shooting. A joint brief of Advancement Project Alliance for Educational Justice Dignity in Schools Campaign, NAACP Legal Defense and Educational Fund. INC. Retrieved from: https://advancementproject.org/resources/policeschools-not-answer-newtown-shooting/

32. Aronowitz, S. V., Kim, B., Aronowitz, T. (2020). A Mixed-Studies Review of the School-to-Prison Pipeline and a Call to Action for School Nurses. Journal of School Nursing, https://doi.org/10.1177/1059840520972003

33. Africaportal. (2018, April. 13). Preventing Boko Haram abductions of schoolchildren in Nigeria. Retrieved from: https://www.africaportal.org/features/preventingboko-haram-abductions- schoolchildren-nigeria/

34. Vanguard. (2020; Feb. 4). The Long Walk to Community Policing in Nigeria. Retrieved from: https://www.vanguardngr.com/2020/02/the-longwalk-to-community-policing-in-nigeria/

35. PRNigeria. (2020, March 16). Police Boss Identifies 5 States for Speedy Community Policing. PRNigeria Retrieved from: https://prnigeria.com/2020/03/13/police-identifiescommunity-policing/

36. Moor, A. (2011). The efficacy of a high school rape prevention program in Israel. Violence and victims, 26(3), 283-295.

37. Foshee, V. A., Reyes, H. L. M., Ennett, S. T., Cance, J. D., Bauman, K. E., \& Bowling, J. M. (2012). Assessing the effects of Families for Safe Dates, a family-based teen dating abuse prevention program. Journal of Adolescent Health, 51(4), 349. 356.

38. Faul, F., Erdfelder, E., Buchner, A., \& Lang, A. G. (2009). Statistical power analyses using $\mathrm{G}^{*}$ Power

3.1: Tests for correlation and regression analyses. Behavior research methods, 41(4), 11491160.

39. Cohen, J. (1988). Statistical power analysis for the behavioral sciences (2nd ed.). New York, NY: Academic 
40. Karlson, C. W., \& Rapoff, M. A. (2009). Attrition in randomized controlled trials for pediatric chronic conditions. Journal of Pediatric Psychology, 34(7), 782-793. https://doi.org/10.1093/jpepsy/jsn122

41. McMahon, S., \& Farmer, G. L. (2011). An Updated Measure for Assessing Subtle Rape Myths. Social Work Research, 35(2): 71-81.

42. Deitz, S. R., Blackwell, K. T., Daley, P. C., \& Bentley, B. J. (1982). Measurement of empathy toward rape victims and rapists. Journal of Personality and Social Psychology, 43(2), 372.

43. Deitz, S. R., Littman, M., \& Bentley, B. J. (1984). Attribution of responsibility for rape: The influence of observer empathy, victim resistance, and victim attractiveness. Sex roles, 10(3-4), 261-280.

44. IBM Corp. (2015). IBM SPSS Statistics for Windows, Version 23.0. Armonk, NY: IBM Corp.

45. Kang, H. (2013). The prevention and handling of the missing data. Korean journal of anesthesiology, 64(5), 402. doi: 10.4097/kjae.2013.64.5.402

46. Stephens, K. A., \& George, W. H. (2009). Rape prevention with college men: Evaluating risk status. Journal of Interpersonal Violence, 24(6), 996-1013. doi:10.1177/0886260508319366

47. Ueland, J. A. (2011). Effects of sexual assault education on college students' rape-supportive attitudes. Honors Program Theses. 47. https://scholarworks.uni.edu/hpt/47

48. Raymond, B. (2010). Problem-Oriented Guides for Police Response Guides Series No. 10. U.S.
Department of Justice, Office of Community Oriented Policing Services. ISBN: 978-1-93567614-0. Retrieved from: https://popcenter.asu.edu/sites/default/files/assignin g_police_officers_to_schools.pdf

49. Broll, R., \& Howells, S. (2019). Community Policing in Schools: Relationship-Building and the Responsibilities of School Resource Officers. Policing: A Journal of Policy and Practice.

50. Omisore, A. G., Omisore, B., Adelekan, B., Afolabi, O. T., Olajide, F. O., Arije, O. O., \& Agunbiade, O. I. (2012). A comparative study of school-based violence and strategies for control in public and private secondary schools in Osun State. Nigerian Journal of Medicine, 21(1), 81-88.

51. Best, N. C., Oppewal, S., \& Travers, D. (2018). Exploring school nurse interventions and health and education outcomes: An integrative review. The Journal of School Nursing, 34(1), 1427.

52. National Association of School Nurses. (2011). The roles of the School Nurse - Position Statement. Retrieved from: http://www.nasn.org/portals/0/positions/2011psrole .pdf

53. Bradley, A. R., Yeater, E. A., \& O’Donohue, W. (2009). An evaluation of a mixed-gender sexual assault prevention program. The Journal of Primary Prevention, 30(6), 697-715. 